\title{
THERMAL CONTROL MATERIALS ON EOIM-3
}

\author{
Miria M. Finckenor \\ Roger C. Linton \\ Rachel R. Kamenetzky \\ Jason A. Vaughn \\ EH15 Space Environment Effects \\ Marshall Space Flight Center, AL 35812
}

\begin{abstract}
Thermal control paints, anodized aluminum, and beta cloth samples were flown on STS46 as part of the Evaluation of Oxygen Interaction with Materials Experiment (EOIM-3). The thermal control paints flown on EOIM-3 include ceramic and polyurethane-based paints. Passively exposed samples are compared to actively heated samples and controlled exposure samples. Optical property measurements of absorptivity, emissivity, and spectrofluorescence are presented for each paint.

Several variations of anodized aluminum, including chromic acid anodize, sulfuric acid anodize, and boric/sulfuric acid anodize were flown on the actively heated trays and the passive exposure trays. The post-flight optical properties are within tolerances for these materials. Also flown were two samples of yellow anodized aluminum. The yellow anodized aluminum samples darkened noticeably.

Samples of aluminized and unaluminized beta cloth, a fiberglass woven mat impregnated with TFE Teflon, were flown with passive exposure to the space environment. Data from this part of the experiment is correlated to observations from LDEF and erosion of the Teflon thin film samples also flown on EOIM-3 and LDEF.
\end{abstract}

\section{INTRODUCTION}

Materials must be tested for durability in the space environment before being approved for use on spacecraft, particularly long-term missions. Thermal control materials, such as paints and anodizations, must maintain their optical properties within certain parameters over the life of the vehicle despite the harsh environment. Ground simulators are available for testing these materials, but it is always beneficial whenever possible to expose materials to the actual space environment for analysis. This is primarily done on short flights on the Space Shuttle, with the samples on a pallet in the cargo bay.

The Evaluation of Oxygen Interaction with Materials Experiment, third flight, or EOIM3 flew on the Space Shuttle mission STS-46 July 31 - August 8, 1992. A pallet in the Shuttle cargo bay (Fig. 1) carried numerous materials samples and fixtures which were exposed to the space environment. The Space Shuttle flew in a bay-forward position for 42 hours near the end of the mission for direct atomic oxygen impingement, exposing the experiment to a fluence of approximately $2.2 \times 10^{20}$ atoms $/ \mathrm{cm}^{2}$. Thermal control coatings were among the 250 samples 
exposed to atomic oxygen, ultraviolet radiation, particulate radiation, thermal cycling, hard vacuum, and micrometeoroid/space debris impacts. These samples have been evaluated for optical property changes caused by space environment exposure, as well as other material property changes.

\section{SPACE ENVIRONMENT}

The low Earth orbit environment consists of atomic oxygen, ultraviolet radiation, particulate radiation, thermal cycling, hard vacuum, and micrometeoroid/space debris particles. The majority of the atomic oxygen exposure was during the EOIM-3 part of the STS-46 mission, when the Space Shuttle flew with the cargo bay oriented into the RAM direction at an altitude of 123-124 nautical miles. Additional atomic oxygen exposure of approximately $1 \times 10^{18}$ atoms $/ \mathrm{cm}^{2}$ occurred during the European Retrievable Carrier (EURECA) deployment, release, and station-keeping. Solar ultraviolet exposure consisted of 30.6 sun hours, with 7.6 sun hours synergistic with the atomic oxygen exposure. Particulate radiation was negligible for the short mission. Thermal cycling of the experiment was measured with thermocouples of varying emissivity (Ref. 2). Passive tray temperatures varied from -5 to $+80{ }^{\circ} \mathrm{C}$ for the mission. To prevent molecular contamination due to the thermal cycling in the vacuum of space, material samples were baked in a vacuum oven for 24 hours prior to flight to evolve any outgassing products. Micrometeoroid/space debris particles impacts were limited to a few small impacts less than $0.25 \mathrm{~mm}$ in diameter.

\section{EXPERIMENT DESCRIPTION AND ANALYSIS}

Three trays containing a total of 138 samples were passively exposed to the space environment. These trays included samples of thermal control paints, anodized aluminum, and beta cloth. Active exposures were performed with three separate trays held at temperatures of 60,120 , and $200{ }^{\circ} \mathrm{C}$ during the atomic oxygen exposure. MSFC also contributed paint samples to the Solar UV trays and the Variable Exposure Trays, which varied the exposure to the ultraviolet radiation and atomic oxygen, respectively.

The Solar UV Experiment consisted of three trays. One tray was open to atomic oxygen and ultraviolet radiation during the entire mission. One tray was shuttered to only expose the samples to atomic oxygen in the presence of ultraviolet radiation. The third tray was shuttered to expose samples only to atomic oxygen with no UV exposure. The Variable Exposure Tray Experiment was intended to expose four trays to 10,20,30, and 40 hours of atomic oxygen. However, a microswitch failed, exposing all four trays to the entire 42 hours of atomic oxygen exposure. These paints were flown with $90 \%$ transmission nickel screens in place. This provided a grid of unexposed paint to measure erosion depth across the sample.

Samples remained in a desiccator prior to optical property measurement to eliminate any humidity effects. Diffuse solar absorptance measurements were made using a Beckman DK-2 spectrophotometer and an AZ Technology laboratory portable spectroreflectometer (LPSR) on both the control and flight samples. Where the samples were partially shielded from the space 
environment with a "half-moon" anodized aluminum cover, measurements were made on both the exposed and unexposed areas. Infrared emittance measurements were made with a GierDunkle DB100 emissometer. A Mettler AT250 balance was used for mass measurements. Spectrofluorescence measurements were obtained using a SLM Aminco SPF-500C dual monochromator spectrofluorometer with a narrow-band excitation of $260 \mathrm{~nm}$ wavelength. Changes in fluorescence properties are described as quenching, stimulated emission of a new or altered color, emission wavelength shift, or enriched emission of the same color. In this paper, quenching simply refers to observed fluorescent intensity decreases rather than any imputed mechanisms of spectral change. Previous studies of the effects of space environment exposure on fluorescence properties can be found in Reference 3 .

\section{THERMAL CONTROL PAINTS}

Thermal control paints exposed on the passive tray include Chemglaze A-276, Aeroglaze A-3200, Aeroglaze IC5755-60, Aeroglaze K-3210, IITRI YB-71, IITRI Z-93 with PS7 and Kasil 2130 potassium silicate binders, Chemglaze Z-306, Aeroglaze Z-3306, Aeroglaze Z-3901, other zinc oxide and zinc orthotitanate formulations, and doped silica black ceramic paint. The paints, unless otherwise noted, flew only on the passively exposed tray. Table 1 contains the optical property data measured on the flight and control samples.

Chemglaze A-276 is a glossy white titanium dioxide paint with a polyurethane binder. Samples of A-276 flew on the passively exposed tray and each of the Solar Ultraviolet and Variable Exposure Trays. It showed typical increased diffuseness with all exposures due to the erosion of the binder. Dektak measurements of the samples flown with $90 \%$ transmission nickel screens show an average thickness loss of $14,000 \AA$ for samples exposed to $2.2 \times 10^{20}$ atomic oxygen atoms $/ \mathrm{cm}^{2}$. Fluorescence measurements showed little difference between the actively controlled tray samples and the passive tray samples, but the control sample fluoresced more strongly in the blue-violet wavelengths (Fig. 2).

Aeroglaze A-3200 glossy white paint was similar to the A-276 in increased diffuseness. No color change was observed in either visible light or black light illumination. Fluorescence quenching did occur, similar to that of the A-276 paint sample.

Aeroglaze IC5755-60 flat black paint faded somewhat due to space exposure with black speckles remaining (Fig. 3). Black light illumination showed stimulated fluorescence in the green wavelengths, similar to the fluorescence of Chemglaze Z-306.

Aeroglaze K-3210 glossy white paint was similar to the A-276 in increased diffuseness. Significant quenching of fluorescence was observed in the blue wavelengths (Fig 4).

IITRI YB-71 paint with zinc orthotitanate pigment and potassium silicate binder flew on the $60{ }^{\circ} \mathrm{C}$ and $120^{\circ} \mathrm{C}$ heated trays as well as the passive exposure trays. No color or surface morphology changes were noted, though paint flaking did occur where the sample fixture may have rubbed the material during flight. Samples passively exposed to the space environment did not change in fluorescence properties.

IITRI Z-93 zinc oxide paint was flown with two variations. The potassium silicate binder PS7 is no longer being manufactured by Sylvania, and Kasil 2130, also a potassium silicate binder, has been proposed as a substitute. Z-93 with the PS7 binder flew on the $60{ }^{\circ} \mathrm{C}$ and $120^{\circ} \mathrm{C}$ heated trays as well as the passive exposure trays. No color change or surface 
texturing was observed. Z-93 with the Kasil 2130 binder flew only on the passively exposed tray and also did not change in color or texture. Slight quenching of fluorescence was noted for both binder variations.

Chemglaze Z-306 is a black carbon and titanium dioxide paint with a polyurethane binder that typically becomes more diffuse when exposed to atomic oxygen due to binder erosion. Exposure to the space environment stimulated green fluorescence by apparently spectrally shifting the broad middle emission band (Fig. 5).

Aeroglaze Z-3306 flat black paint became a darker velvety black due to atomic oxygen erosion. Spectrofluorescence measurements show quenching of ultraviolet and red emission bands and a shift in the broad middle fluorescence band to longer wavelengths. This is in agreement with black light observations of stimulated color emission.

Aeroglaze Z-3901 aluminum-colored paint did exhibit a slight color change. This paint also exhibited a significant change in emittance, from 0.29 to 0.36 . Nearly all fluorescence in the flight sample was quenched compared to the control sample.

A development paint of zinc oxide pigment with potassium silicate binder was tested. This paint varies from Z-93 in that the zinc oxide is of a finer particle size and the pigment-tobinder ratio (PBR) is adjusted for a lower solar absorptance. This sample exhibited no color change or surface texturing due to space environment exposure. Flaking of the paint did occur where the sample fixture may have abraded the material during flight. Slight quenching of fluorescence was noted.

Another development paint of zinc orthotitanate with potassium silicate binder was formulated in a similar fashion to the zinc oxide sample, with finer particle size and higher PBR. It also did not exhibit any color or surface changes. Black light fluorescence did not appear to have changed.

Doped silica black ceramic paint, also under development, did not appear affected by exposure to the space environment. It remained a diffuse black color.

\section{ANODIZED ALUMINUM}

A variety of anodizations were tested in the space environment. Chromic acid anodized, sulfuric acid anodized, and boric/sulfuric acid anodized samples were flown on all three temperature controlled trays as well as the passively exposed tray. The substrates were aluminum alloy 6061-T6. There were two variations on the boric/sulfuric acid anodization with 10 and 12 minute processing time. The post-flight optical properties (Table 1) are within thermal design tolerances for these materials, with the exception of the chromic acid anodized aluminum flown on the $120^{\circ} \mathrm{C}$ heated tray. Possible contamination effects on this sample are being studied. No color changes were noted for any flight sample. Ellipsometry and other analyses are underway to determine if any changes in the oxidation layer occurred due to space environment exposure.

Also flown on the passively exposed tray were two samples of yellow organic dye chromic acid anodized aluminum. Organic-dyed anodized aluminum samples may be used as a gauge of incident solar UV radiation and for comparison to ground-based environmental exposure tests. Similar material samples have been observed to darken significantly after ultraviolet radiation exposure in the laboratory and to fade considerably as a result of lab 
atomic oxygen exposure in the absence of ultraviolet radiation. Samples exposed to UV radiation in the laboratory and subsequently exposed to thermal energy atomic oxygen indicate less darkening. For the reported levels of atomic oxygen exposure and UV radiation during the EOIM-3 mission, the samples are darker than predicted from laboratory exposure to comparable levels of UV radiation and then atomic oxygen. Figure 6 is of a half-exposed yellow chromic acid anodized aluminum sample, with the exposed half noticeably darkened. Figure 7 shows the decrease in reflectance in the visible wavelengths of the exposed flight sample as compared to the control sample.

\section{BETA CLOTH}

Beta cloth is a fiberglass mat impregnated with TFE Teflon for flexibility and reduction in particle generation. It is generally used in multi-layer insulation thermal blankets to provide a refurbishable, thermally compatible cover and protect the underlying aluminized Mylar or aluminized Kapton layers from atomic oxygen attack. Three different types of beta cloth were flown on EOIM-3.

Two types of "plain" beta cloth were exposed. Chemical Fabrics Corporation (Chemfab) provided samples of Chemglas 250, which meets Rockwell specification \#MB0135027 and is used in the Space Shuttle cargo bay liners. Samples of beta cloth were taken from an unexposed section of the LDEF Experiment \#S1005, the Transverse Flat-Plate Heat Pipe Experiment and flown. These beta cloth samples were flown with 5 layers of double aluminized Kapton with Dacron netting spacers underneath. No degradation of the multi-layer insulation was observed. Microscopic analysis of the Teflon erosion was found to be typical of short-term exposure to atomic oxygen.

These samples were measured for solar absorptance with the aluminized Kapton multilayer insulation as a standardized backing. The control Chemglas 250 beta cloth sample $\alpha_{s}$ was 0.200 , while the flight sample $\alpha_{\mathrm{s}}$ was 0.197 . The control and flight S1005 beta cloth samples had a measured solar absorptance of 0.207 and 0.204 , respectively. Infrared emittance was 0.90 for all control and flight samples.

Samples of Chemglas 250F-80 aluminized beta cloth were flown with the aluminized side down. Aluminized beta cloth is being proposed for long-term spacecraft and eliminates the need for a light block layer in a thermal blanket. The solar absorptance of the aluminized beta cloth control sample was 0.357 on the non-metallized side. The two flight samples had measured solar absorptance of 0.363 and 0.366 . Infrared emittance was 0.90 for all control and flight samples.

The optical property results, however, should not be misinterpreted as full approval of beta cloth for use on long-term spacecraft. These flight samples were exposed on a short duration LEO mission to a very low dose of ultraviolet radiation in presence of atomic oxygen. Laboratory tests of some types of beta cloth in an ultraviolet radiation only environment indicate yellowing attributed to a silicone additive used for increased flexibility of the cloth. Solar absorptance of aluminized beta cloth increased from 0.31 to 0.36 following exposure to 400 equivalent sun hours (ESH) of ultraviolet radiation. Solar absorptance of plain beta cloth increased in solar absorptance 0.02 and 0.03 following UV exposures of 400 and $700 \mathrm{ESH}$, respectively. This yellowing has been observed to decrease, if not disappear, following subsequent atomic oxygen exposure. 


\section{INTERIM CONCLUSIONS}

Preliminary analysis of the ceramic binder paints indicate good durability in the space environment with respect to optical properties. Erosion of the paints with a polyurethane binder were as predicted. Increased diffusivity of the Chemglaze A-276 and Z-306 paints were similar to those exposed to atomic oxygen on the Long Duration Exposure Facility and earlier short duration Shuttle missions. The Aeroglaze IC-5755-60 flat black paint faded noticeably due to space environment exposure, while the Z-3901 paint experienced a significant change in emittance.

Anodizations performed well with the exception of the yellow organic dye chromic acid anodized aluminum and the chromic acid anodized aluminum flown on the $120^{\circ} \mathrm{C}$ heated tray. Possible contamination effects are under investigation. The remaining anodizations were within thermal design tolerances for solar absorptance and infrared emittance. Beta cloth also performed well, maintaining its optical properties in the presence of atomic oxygen.

\section{REFERENCES}

1. Leger, Lubert, Koontz, S., Visentine, J., and Hunton, D., "An Overview of Evaluation of Oxygen Interaction with Materials III Experiment", LDEF Materials Results for Spacecraft Applications Conference, Oct. 26-28, 1992.

2. Leger, Lubert, "Evaluation of Oxygen Interaction with Materials III (EOIM-III) Flight Experiment Update," Memo \#ES5-93-118, July 1993.

3. Linton, R.C., Whitaker, A.F., and Kamenetzky, R.R., "Fluorescence Observations of LDEF Exposed Materials as an Indicator of Induced Material Reactions", LDEF Materials Results for Spacecraft Applications Conference, Oct. 1992. 


\begin{tabular}{|c|c|c|c|c|c|c|c|}
\hline Sample & Environment & Control $\alpha_{s}$ & Exposed $\alpha_{s}$ & $\Delta a_{3}$ & Control $\varepsilon_{\mathrm{gR}}$ & Exposed $\varepsilon_{\mathrm{gz}}$ & $\Delta \varepsilon_{\mathrm{pR}}$ \\
\hline \multirow[t]{3}{*}{ A-276 } & Passive & 0.276 & 0.283 & +0.007 & 0.89 & 0.91 & +0.02 \\
\hline & $A O+U V$ & 0.276 & 0.275 & -0.001 & 0.89 & 0.91 & +0.02 \\
\hline & AO only & 0.276 & 0.273 & .0 .003 & 0.89 & 0.90 & +0.01 \\
\hline A-3200 & Passive & 0.273 & 0.280 & +0.007 & 0.90 & 0.90 & 0.00 \\
\hline IC5755-60 & Passive & 0.971 & 0.938 & -0.033 & 0.90 & 0.92 & +0.02 \\
\hline K.3210 & Passive & 0.269 & 0.264 & -0.005 & 0.90 & 0.90 & 0.00 \\
\hline \multirow[t]{3}{*}{ YB-7I } & Passive & 0.129 & 0.131 & +0.002 & 0.88 & 0.89 & +0.01 \\
\hline & $60^{\circ} \mathrm{C}$ & 0.136 & 0.129 & -0.007 & 0.88 & 0.88 & 0.00 \\
\hline & $120^{\circ} \mathrm{C}$ & 0.136 & 0.135 & $=0.001$ & 0.88 & 0.88 & 0.00 \\
\hline \multirow[t]{3}{*}{ Z-93/PS7 Binder } & Passive & 0.182 & 0.180 & -0.002 & 0.91 & 0.91 & 0.00 \\
\hline & $60^{\circ} \mathrm{C}$ & 0.172 & 0.156 & -0.016 & 0.91 & 0.91 & 0.00 \\
\hline & $120^{\circ} \mathrm{C}$ & 0.172 & 0.160 & -0.012 & 0.91 & 0.91 & 0.00 \\
\hline Z-93/Kasil 2130 & Passive & 0.139 & 0.138 & -0.001 & 0.89 & 0.89 & 0.00 \\
\hline \multirow[t]{3}{*}{$Z-306$} & Passive & 0.938 & 0.965 & +0.027 & 0.91 & 0.94 & +0.03 \\
\hline & $A O+U V$ & 0.938 & 0.967 & +0.029 & 0.91 & 0.94 & +0.03 \\
\hline & AO only & 0.938 & 0.969 & +0.031 & 0.91 & 0.94 & +0.03 \\
\hline Z.3306 & Passive & 0.960 & 0.991 & +0.031 & 0.90 & 0.92 & +0.02 \\
\hline Z-3901 & Passive & 0.234 & 0.252 & +0.018 & 0.29 & 0.36 & +0.07 \\
\hline Doped Silica & Passive & 0.969 & 0.964 & -0.005 & 0.91 & 0.91 & 0.00 \\
\hline Zinc Oxide & Passive & 0.170 & 0.162 & -0.008 & 0.91 & 0.91 & 0.00 \\
\hline Zinc Orthotitanate & Passive & 0.118 & 0.116 & -0.002 & 0.91 & 0.91 & 0.00 \\
\hline \multirow{4}{*}{$\begin{array}{l}\text { Boric/Sulfuric Acid } \\
\text { Anodized Aluminum } \\
10 \text { min. }\end{array}$} & & 0.238 & 0.240 & +0.002 & 0.31 & 0.31 & 0.00 \\
\hline & $60^{\circ} \mathrm{C}$ & 0.238 & $0.24 I$ & +0.003 & 0.31 & 0.31 & 0.00 \\
\hline & $120^{\circ} \mathrm{C}$ & 0.238 & 0.240 & +0.002 & 0.31 & 0.31 & 0.00 \\
\hline & $200^{\circ} \mathrm{C}$ & 0.238 & 0.244 & +0.002 & 0.31 & 0.30 & -0.01 \\
\hline \multirow{2}{*}{$\begin{array}{l}\text { Boric/Sulfuric Acid } \\
\text { Anodized Aluminum } \\
12 \text { min. }\end{array}$} & Passive & 0.254 & 0.253 & -0.001 & 0.46 & 0.44 & -0.02 \\
\hline & $60^{\circ} \mathrm{C}$ & 0.254 & 0.253 & -0.001 & 0.46 & 0.46 & 0.00 \\
\hline \multirow{4}{*}{$\begin{array}{l}\text { Chromic Acid } \\
\text { Anodized Aluminum }\end{array}$} & Passive & 0.357 & 0.366 & +0.009 & 0.70 & 0.70 & 0.00 \\
\hline & $60^{\circ} \mathrm{C}$ & 0.357 & 0.375 & +0.018 & 0.70 & 0.70 & 0.00 \\
\hline & $120^{\circ} \mathrm{C}$ & 0.357 & 0.431 & +0.074 & 0.70 & 0.70 & 0.00 \\
\hline & $200^{\circ} \mathrm{C}$ & 0.357 & 0.360 & +0.003 & 0.70 & 0.70 & 0.00 \\
\hline \multirow[t]{4}{*}{$\begin{array}{l}\text { Sulfuric Acid } \\
\text { Anodized Aluminum }\end{array}$} & Passive & 0.474 & 0.473 & -0.001 & 0.85 & 0.85 & 0.00 \\
\hline & $60^{\circ} \mathrm{C}$ & 0.474 & 0.487 & +0.013 & 0.85 & 0.86 & +0.01 \\
\hline & $120^{\circ} \mathrm{C}$ & 0.474 & 0.481 & +0.007 & 0.85 & 0.85 & 0.00 \\
\hline & $200^{\circ} \mathrm{C}$ & 0.474 & 0.466 & .0 .008 & 0.85 & 0.85 & 0.00 \\
\hline $\begin{array}{l}\text { Yellow Organic } \\
\text { Dye/Chromic }\end{array}$ & Passive & 0.458 & 0.483 & +0.025 & 0.79 & 0.79 & 0.00 \\
\hline
\end{tabular}

Table 1. Optical Properties of Thermal Control Coatings 


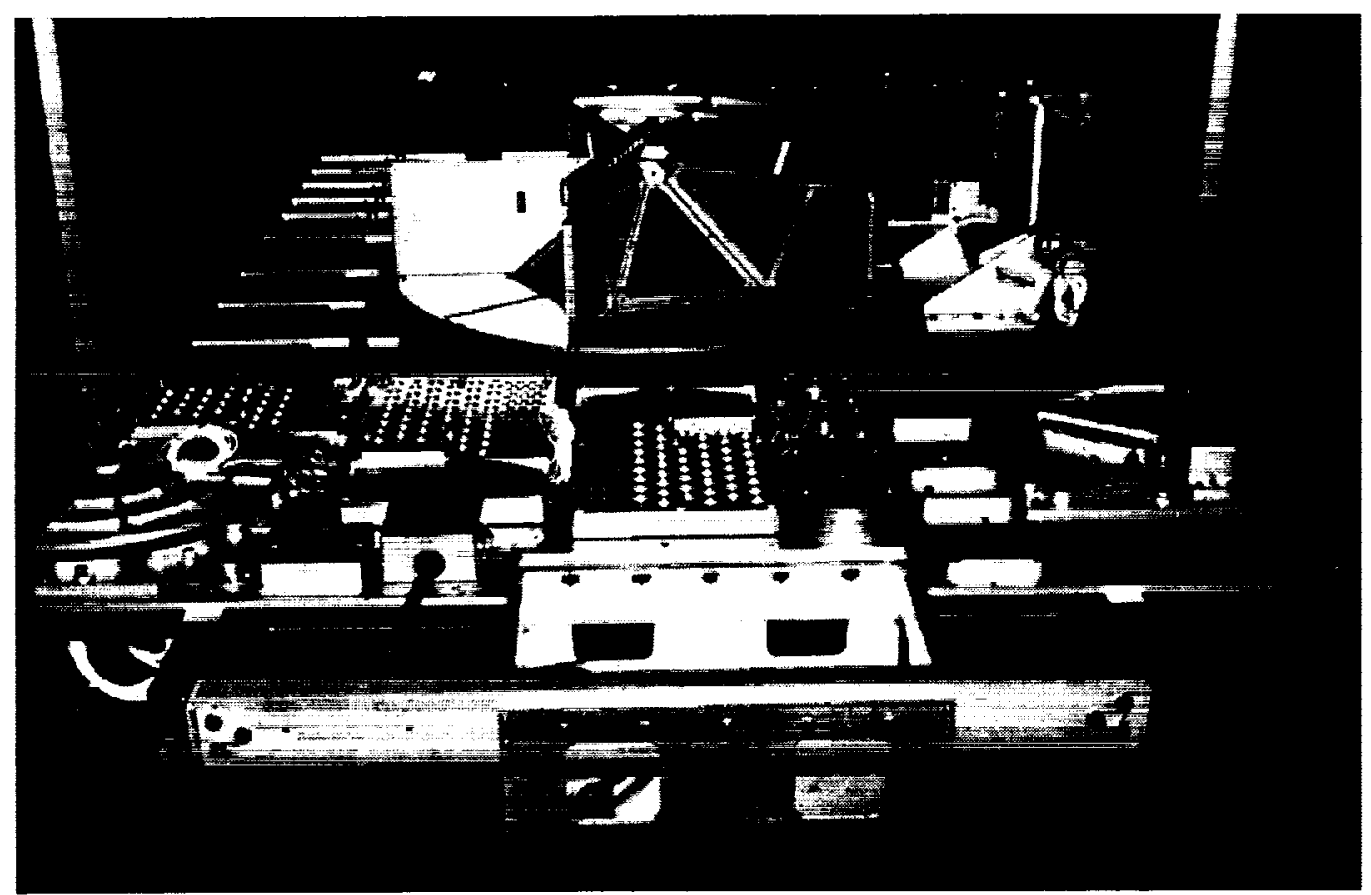

Fig. 1 EOIM-3 Pallet

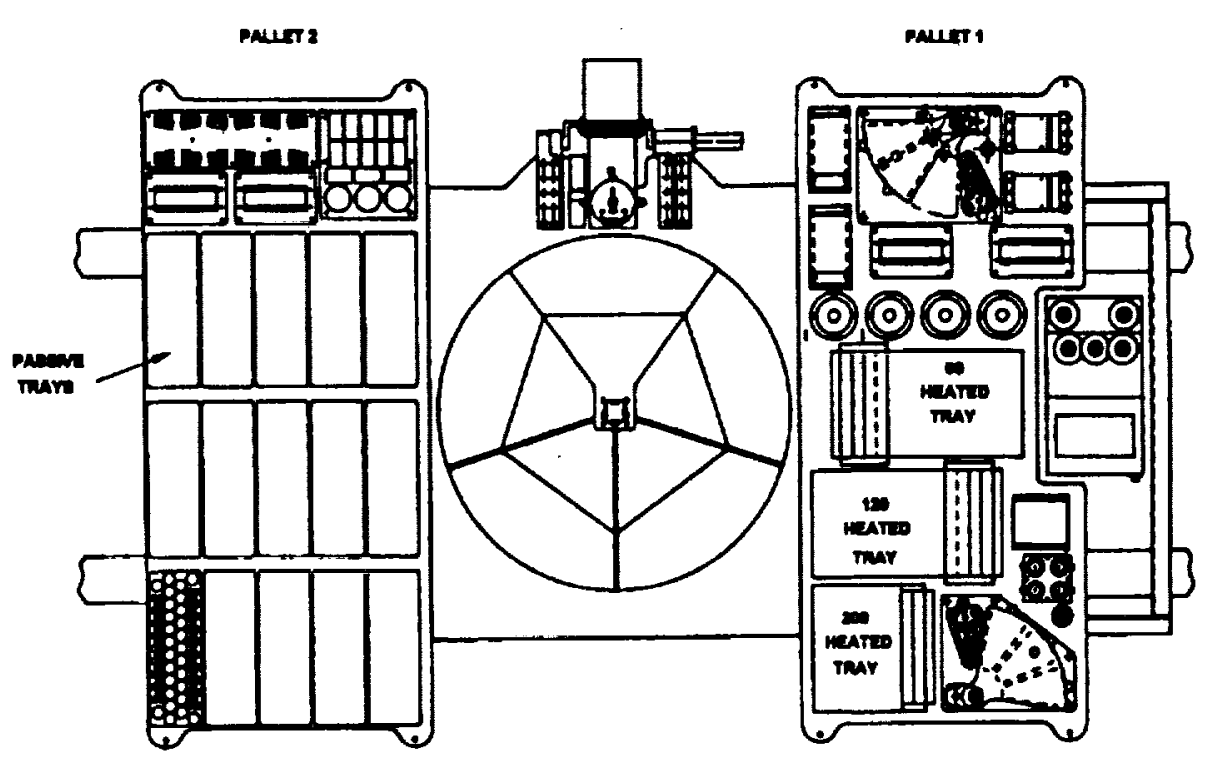




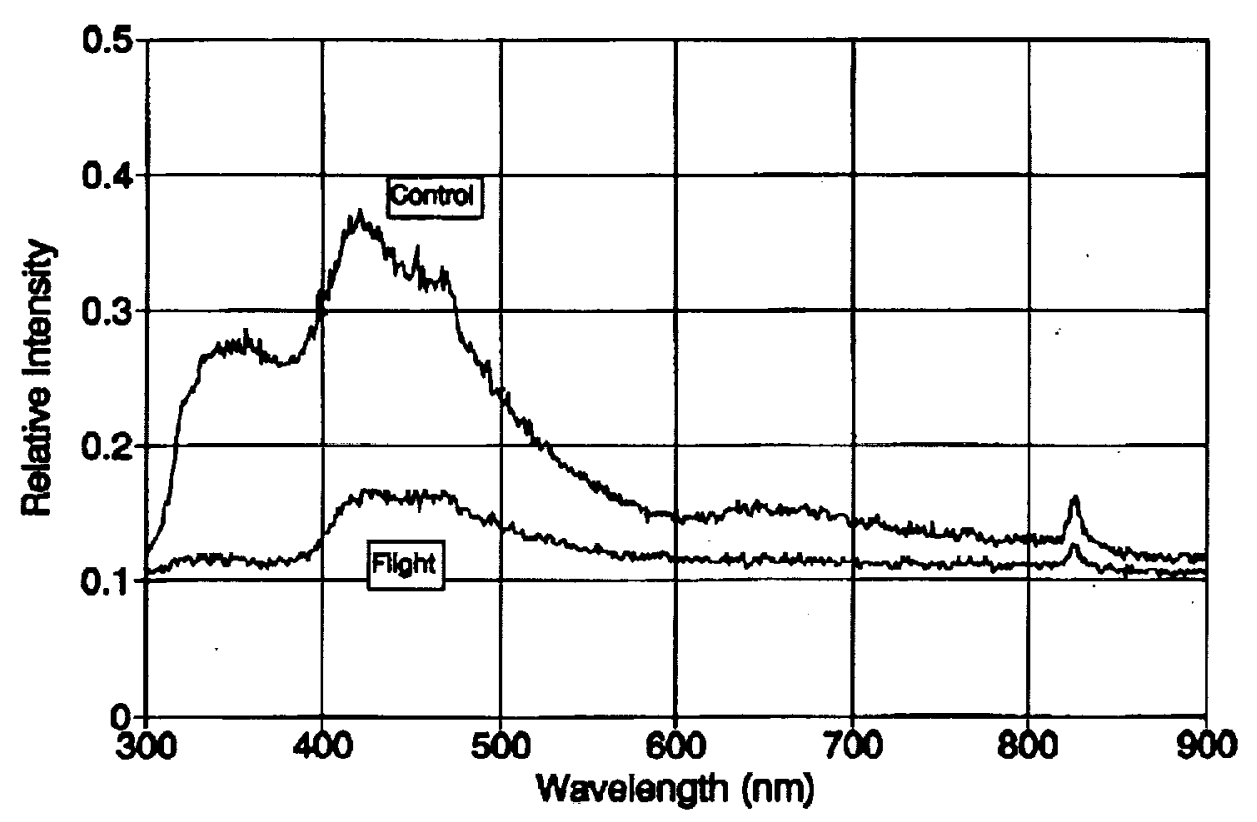

Fig. 2 A-276 Spectrofluorescence

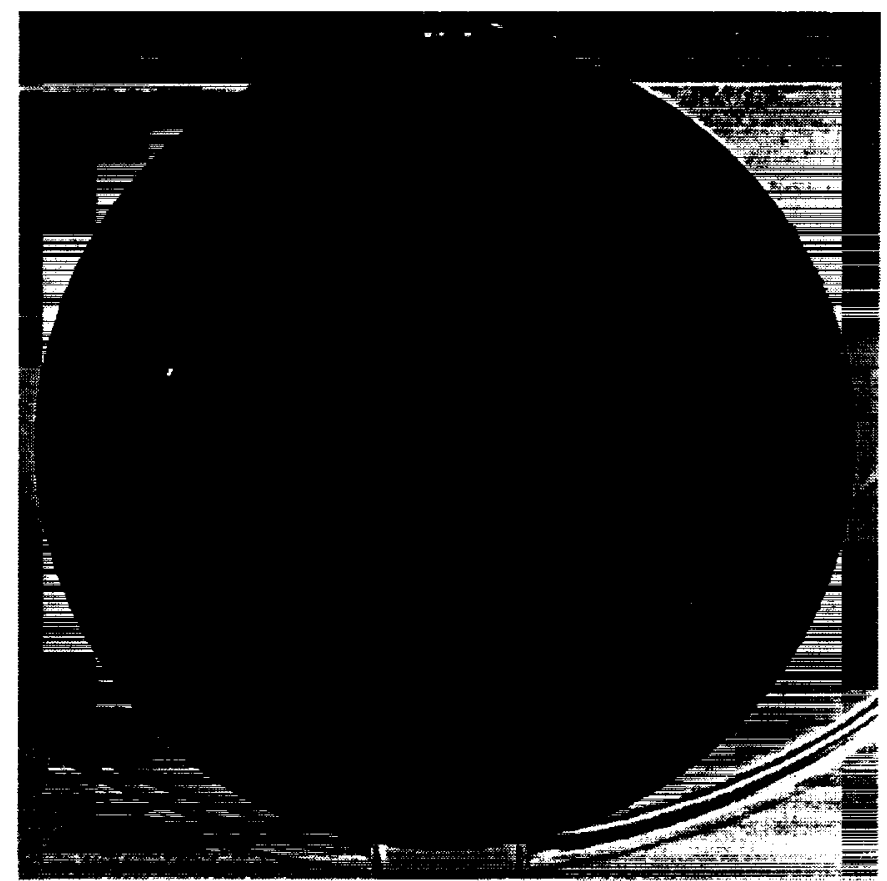

Fig. 3 IC5755-60C Paint 


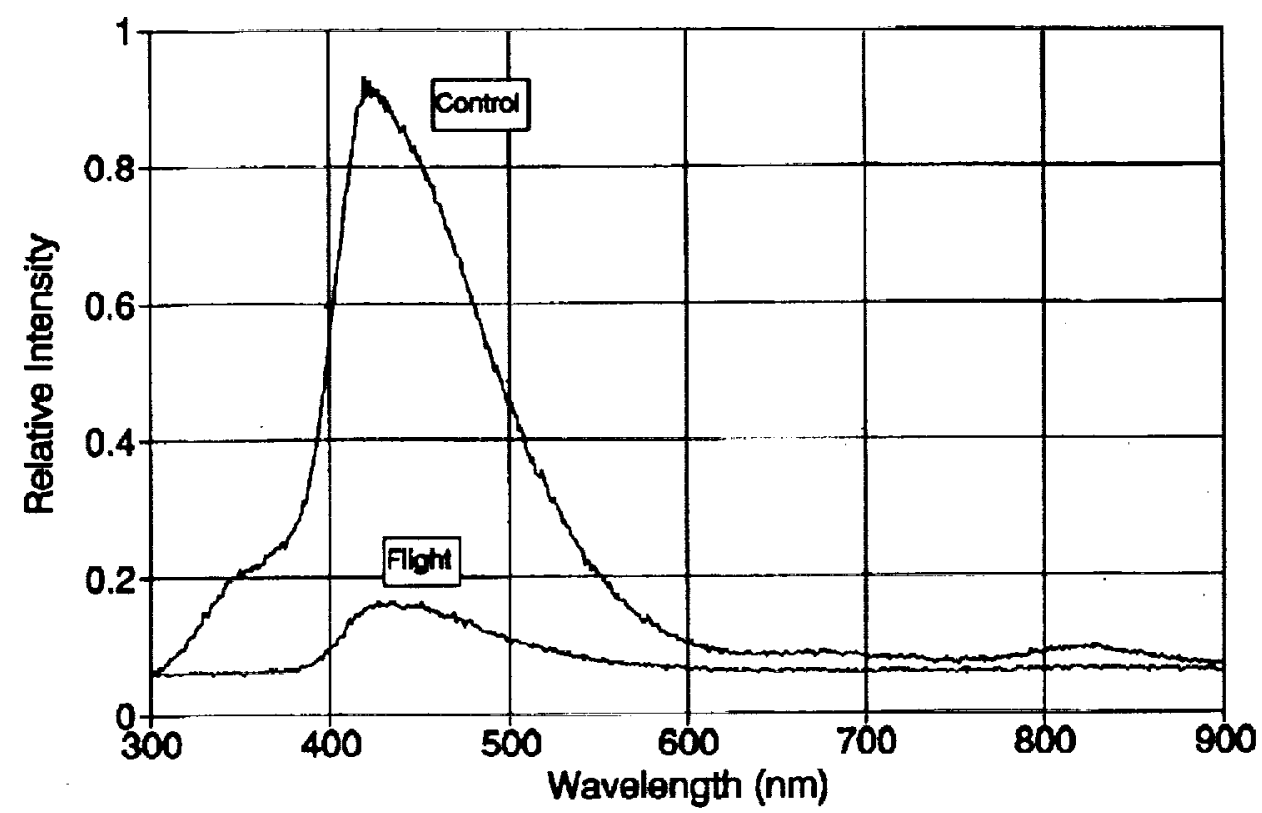

Fig. 4 K-3210 Spectrofluorescence

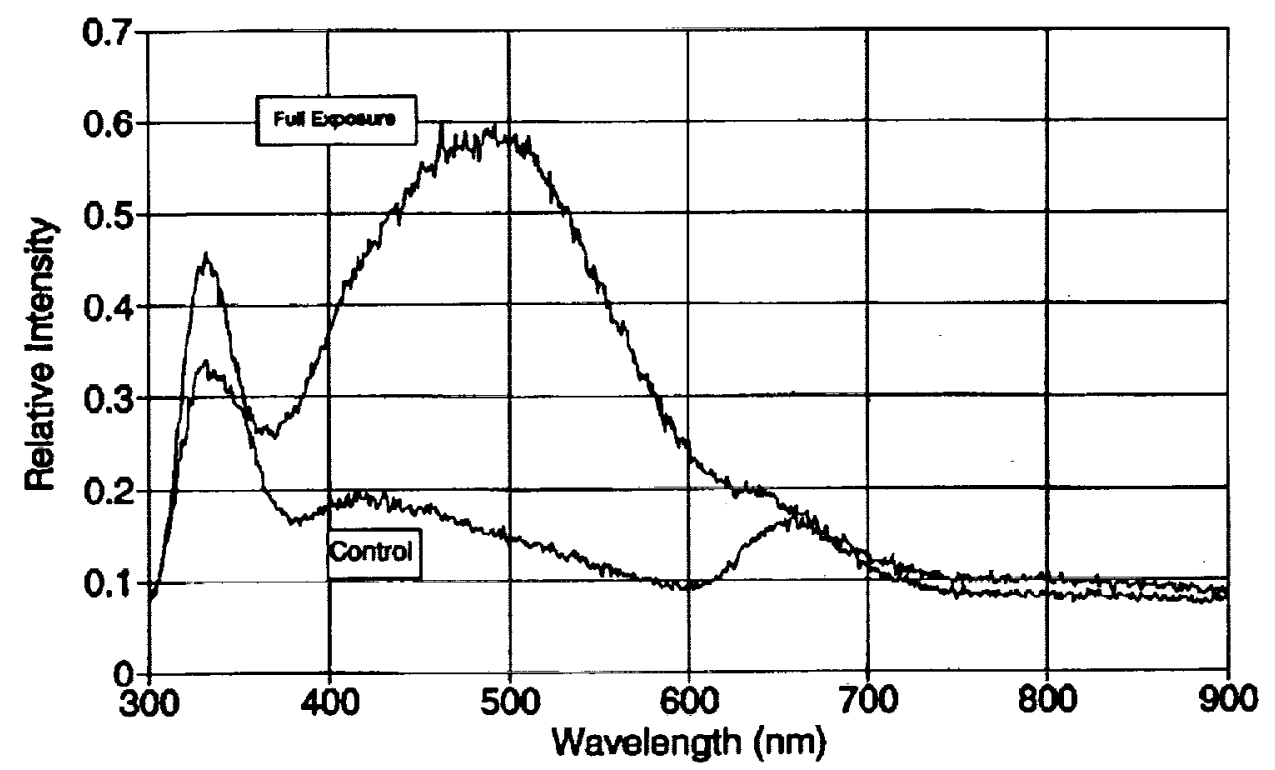

Fig. 5 Z-306 Spectrofluorescence 


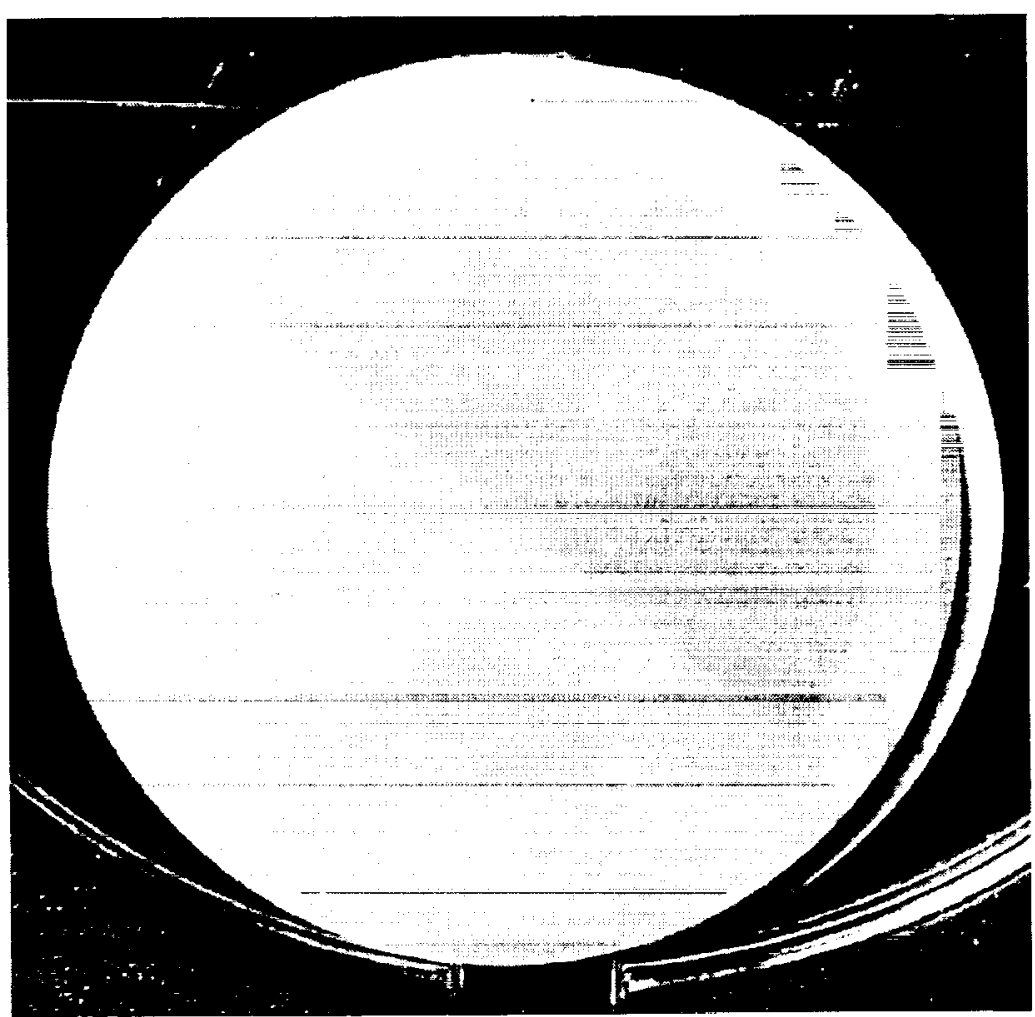

Fig. 6 Yellow organic dye chromic acid anodized aluminum

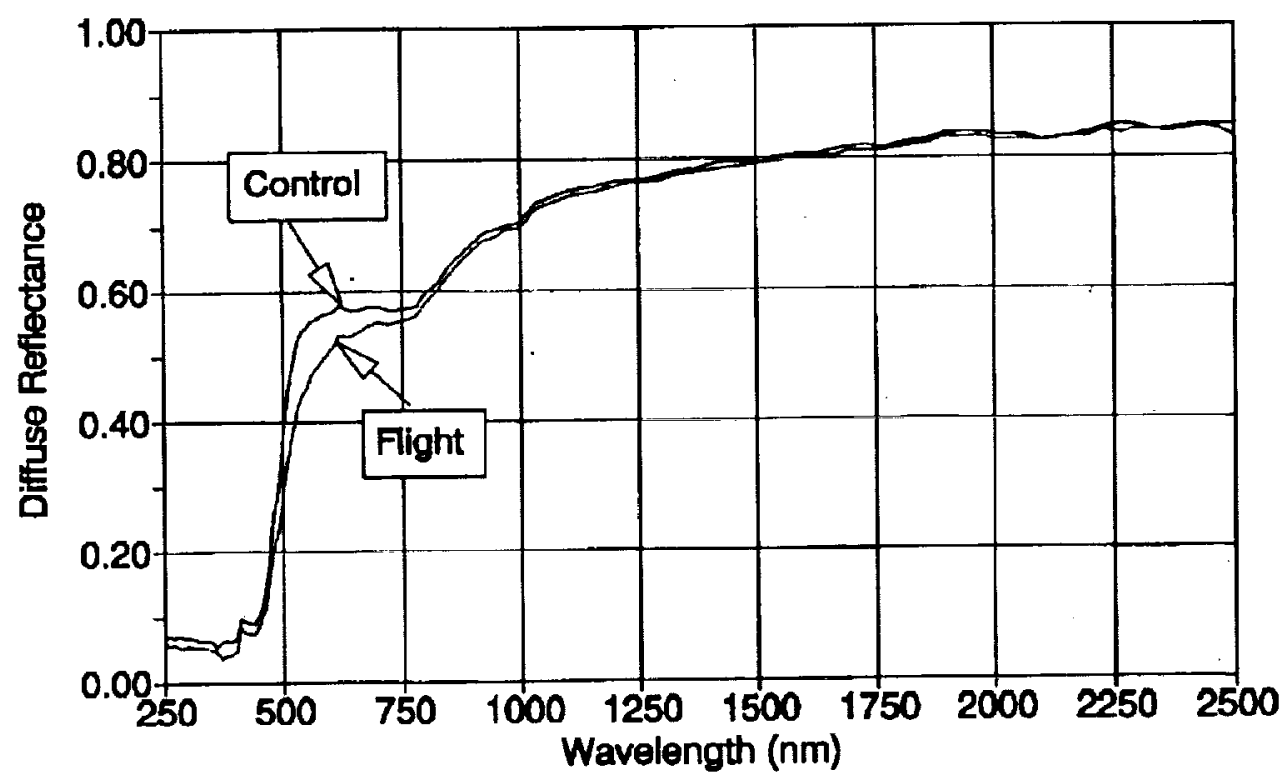

Fig. 7 Diffuse reflectance, control and flight

Yellow organic dye chromic acid anodized aluminum 


. , ,

